\title{
Detecção de Fusarium spp. e Trichoderma spp. e antagonismo de Trichoderma sp. em soja sob plantio direto
}

\section{Detection of Fusarium spp. and Trichoderma spp. and antagonism of Trichoderma sp. in soybean under no-tillage}

\author{
Paola Mendes Milanesi ${ }^{1 *}$; Elena Blume ${ }^{2}$; Marlove Fátima Brião Muniz²; Lia Rejane \\ Silveira Reiniger ${ }^{3}$; Zaida Ines Antoniolli ${ }^{4}$; Emanuele Junges ${ }^{5}$; Manoeli Lupatini ${ }^{6}$
}

\begin{abstract}
Resumo
Este trabalho objetivou i) quantificar a ocorrência de Fusarium spp. e Trichoderma spp. em solo rizosférico, com e sem sintomas de Síndrome da Morte Súbita (SMS), em oito genótipos de soja; ii) identificar morfologicamente Fusarium spp. de raízes; iii) avaliar relações antagônicas entre Trichoderma e Fusarium, isolados de solo rizosférico e raízes de plantas com e sem sintomas de SMS, respectivamente e $i v$ ) caracterizar, através da região ITS1-5.8S-ITS2 do rDNA, os isolados de Trichoderma spp. com melhor desempenho no teste de confrontação direta. As coletas de solo e raízes foram realizadas em uma área experimental localizada em Cruz Alta, RS, Brasil. Em laboratório, foram realizadas diluições seriais das amostras de solo, contagem do número de Unidades Formadoras de Colônias (UFCs $/ \mathrm{g}^{-1}$ de solo rizosférico) e isolamento para identificação de isolados de Fusarium spp. e Trichoderma spp. e teste de confrontação direta. Houve diferença significativa entre as populações de Trichoderma spp. em solo rizosférico de plantas com e sem sintomas de SMS. Para a população de Fusarium spp., foi constatada diferença significativa apenas em solo rizosférico de plantas sem sintomas da doença. Em raízes doentes, foram identificadas as espécies $F$. solani, F. avenaceum, F. graminearum, F. oxysporum e F. verticillioides. No teste de confrontação direta, oito isolados de Trichoderma spp. apresentaram o melhor desempenho no antagonismo a Fusarium spp. Os isolados de Trichoderma spp. provenientes de plantas com sintomas de SMS mostraram maior eficiência de controle in vitro. Esses isolados apresentaram alta similaridade com espécies do agregado $T$. koningii.

Palavras-chave: Glycine $\max$ (L.) Merrill, fungos, população, podridão radicular, controle biológico
\end{abstract}

\footnotetext{
Abstract

This study aimed $i$ ) to quantify the occurrence of Fusarium spp. and Trichoderma spp. in rhizospheric soil, with and without symptoms of Sudden Death Syndrome (SDS) in eight soybean genotypes;

${ }^{1}$ Eng $^{\mathrm{a}}$ Agr ${ }^{\mathrm{a}}$, Pós-Doutoranda em Ciência do Solo, PDJ/CNPq, Dept ${ }^{\mathrm{o}}$ de Solos, Laboratório de Biotransformações do Carbono e do Nitrogênio, Universidade Federal de Santa Maria, UFSM, Centro de Ciências Rurais, CCR, Santa Maria, RS. E-mail: paola.

${ }^{2}$ Prof $^{\text {as }}$ Associada de Fitopatologia, Dept ${ }^{\circ}$ de Defesa Fitossanitária, UFSM/CCR, Santa Maria, RS. E-mail: elenablu@gmail.com; marlovemuniz@yahoo.com.br

${ }^{3}$ Prof $^{a}$ Associada de Melhoramento Vegetal, Dept ${ }^{\circ}$ de Fitotecnia, UFSM/CCR, Santa Maria, RS. E-mail: liarejanesilveirareiniger@

${ }^{4}$ Prof $^{a}$ Associada de Biologia do Solo, Dept ${ }^{\circ}$ de Solos, Laboratório de Biologia do Solo e do Ambiente, UFSM/CCR, Santa Maria, RS. E-mail:. zantoniolli@gmail.com

${ }^{5}$ Eng $^{\mathrm{a}} \mathrm{Agr}^{\mathrm{a}}$, Discente de Doutorado em Agronomia, Dept ${ }^{\circ}$ de Defesa Fitossanitária, Laboratório de Fitopatologia, UFSM/CCR, Santa Maria, RS. E-mail: manujunges@yahoo.com.br

${ }^{6}$ Eng $^{\mathrm{a}}$ Agr ${ }^{\mathrm{a}}$, Discente de Doutorado em Ciência do Solo, Bolsista CAPES. Dept ${ }^{\mathrm{o}}$ de Solos, Laboratório de Biologia do Solo e do Ambiente, UFSM/CCR, Santa Maria, RS. E-mail: mlupatini@gmail.com
} milanesi@gmail.com yahoo.com.br

* Autora para correspondência 
ii) morphologically identify isolates of Fusarium spp. from plants roots with SDS; iii) evaluate the antagonism between Trichoderma spp. and Fusarium spp. isolates from rhizospheric soil and roots from with and without SDS, respectively; and $i v$ ) characterize through the ITS1-5.8S-ITS2 region of rDNA the isolates of Trichoderma spp. with better performance in the direct confrontation. The sampling of soil and roots was performed in an experimental area located in Cruz Alta, RS, Brazil. In the laboratory, serial dilutions of soil samples, counting of the number of Colony Forming Units (UFCs $/ \mathrm{g}^{-1}$ of rhizospheric soil) were performed as well as isolation for identification of isolates of Fusarium spp. and Trichoderma spp. and testing of direct confrontation. There were significant differences between the population of Trichoderma spp. in the rhizosphere of plants with and without symptoms of SDS. For the population of Fusarium spp., significant difference was observed only in the rhizosphere of plants without symptoms of SDS. In diseased roots the following species were identified: F. solani, $F$. avenaceum, $F$. graminearum, $F$. oxysporum and $F$. verticillioides. In the test of direct confrontation, eight isolates of Trichoderma spp. achieved the best performance in the antagonism to Fusarium spp. and Trichoderma spp. from areas with symptoms of SDS had a higher control efficiency in vitro. These isolates showed high similarity to the species of $T$. koningii agregate.

Key words: Glycine $\max (\mathrm{L}$.) Merril, fungi, population, root rot, biological control

\section{Introdução}

Entre as doenças que podem estar associadas à soja (Glycine max (L.) Merrill), a Podridão Vermelha da Raiz (PVR) ou Síndrome da Morte Súbita (SMS), causada pelo complexo Fusarium solani (Mart.) Sacc. (AOKI; O'DONNELL; SCANDIANI, 2005), é uma das mais importantes em função do difícil controle. A SMS se caracteriza por manchas avermelhadas, mais visíveis na raiz principal e, geralmente, localizadas a 1 ou $2 \mathrm{~cm}$ abaixo do nível do solo. Com a evolução da infecção, é observada uma expansão da lesão, que passa a circundar a raiz, assumindo coloração castanho-avermelhada escura e, à medida que as lesões evoluem, pode ser observada uma massa azulada formada por conídios do patógeno (FREITAS; MENEGHETTI; BALARDIN, 2004). Perdas causadas pela SMS dependem de vários fatores, incluindo o estádio de desenvolvimento da planta no momento da infecção pelo patógeno, genótipo utilizado e condições ambientais existentes (ROY et al., 1997).

$\mathrm{Na}$ rizosfera existe uma comunidade microbiana complexa na qual uma grande variedade de interações é desenvolvida. Essa região possui características de composição e estrutura influenciadas pelo ciclo vegetativo e umidade do solo (PEREIRA, 2000). Nesse ambiente, além dos micro-organismos patogênicos, também existem fungos, bactérias e actinobactérias que possuem atividade contra fitopatógenos, a partir da produção de metabólitos antimicrobianos secundários (antibiose), enzimas líticas, entre outros (RAAIJMAKERS et al., 2009).

Nesse sentido, um método que pode ser empregado contra patógenos de solo é o controle biológico, sendo o gênero Trichoderma um dos mais utilizados, representando fungos não-patogênicos que exercem antagonismo a vários fitopatógenos através do parasitismo e/ou antibiose. Esses fungos têm sido utilizados com bastante sucesso como agentes de biocontrole, promotores de crescimento e na melhoria da germinação e sanidade de sementes (ETHUR et al., 2006). De acordo com Howel (2003), espécies de Trichoderma são capazes de suprimir o desenvolvimento de vários organismos fitopatogênicos, tais como Pythium ultimum Trow 1901, Rhizoctonia solani J.G. Kühn 1858 e Phytophthora spp. e seus mecanismos antagonistas podem ser influenciados pelo tipo de solo, condições de temperatura e umidade, além da microbiota associada.

Fungos do gênero Trichoderma também são relatados como nativos na rizosfera de algumas culturas, como de citros (GESHEVA, 2002), de batata, de algodão (SIVAN; CHET, 1989) e de tomate (LARKIN; FRAVEL, 1998). A capacidade deste fungo em colonizar esse ambiente foi comprovada (COOK, 1993; ETHUR et al., 2008), assim como sua correlação negativa com a incidência de 
doenças radiculares em crisântemo (MENEZES, 2007). No entanto, há carência de informações sobre sua caracterização e interação com Fusarium spp. em áreas cultivadas com soja, assim como a potencialidade de isolados desse antagonista, obtidos de solo de tais áreas, no controle de SMS.

O presente estudo teve por objetivos quantificar as populações de Fusarium spp. e Trichoderma spp. em solo rizosférico de plantas com e sem sintomas de SMS; identificar morfologicamente os isolados de Fusarium obtidos; selecionar e caracterizar, através da região ITS1-5.8S-ITS2 do rDNA, isolados de Trichoderma com capacidade antagônica a Fusarium spp. com potencial para uso futuro no manejo de SMS.

\section{Material e Métodos}

Amostras de solo rizosférico e raízes de soja (Glycine max (L.) Merrill) (safra 2008/2009) foram coletadas em uma área experimental da Fundação Centro de Experimentação e Pesquisa Fecotrigo (FUNDACEP - CCGL), em Cruz Alta - RS, conduzida sob sistema plantio direto há, aproximadamente, 23 anos. O solo da área onde foram realizadas as coletas está classificado como um Latossolo Vermelho distrófico típico argiloso (EMBRAPA, 1999). A classificação climática, segundo Köeppen, é Cfalg2, ou seja, subtropical úmido sem estiagem típica. A temperatura média do mês mais quente é superior a $22^{\circ} \mathrm{C}$ e do mês mais frio é superior a $3{ }^{\circ} \mathrm{C}$ e inferior a $18{ }^{\circ} \mathrm{C}$. A precipitação média anual é maior do que 1600 mm, com tendência de maiores precipitações na primavera e no verão (MORENO, 1961).

Foram coletadas amostras de solo na profundidade de 0-0,10 m, nas parcelas experimentais, para a sua caracterização química e física. Essas determinações foram realizadas no Laboratório de Análise de Solos da Universidade Federal de Santa Maria. O solo da área experimental apresentou em média $500 \mathrm{~g} \mathrm{~kg}^{-1}$ de argila, portanto, pertencente à Classe Textural 2 (CQFS - RS/SC, 2004). As características químicas do solo na mesma camada foram: $\mathrm{pH}$ : 5,0; matéria orgânica do solo (MOS): 3,8\%; P: 1,72 $\mathrm{mg} \mathrm{dm}^{-3} ; \mathrm{K}$ : 0,414 cmolc dm dm $^{-3}$ Al: 0,2 cmolc dm ${ }^{-3}$; Ca: 5,1 cmolc $\mathrm{dm}^{-3} ; \mathrm{Mg}: 2,1 \mathrm{cmolc} \mathrm{dm}^{-3}$; e CTC: $12,0 \%$.

Nessa área, a rotação de culturas incluía soja/ milho durante o verão e azevém ou trigo nos meses de inverno. Durante o estádio de pleno enchimento das vagens da soja $\left(\mathrm{R}_{5}\right)$ (FEHR; CAVINESS, 1977), foram coletadas nas parcelas experimentais (cada uma com área de $25 \mathrm{~m}^{2}$ ) aleatoriamente, quatro plantas com sintomas e quatro sem sintomas de SMS, dos seguintes genótipos oriundos de programas de melhoramento genético: CEPS 06006 RR, CEPS 06002 RR, FUNDACEP 53 RR, CEPS 06010 RR, CEPS 06005 RR, CEPS 06015 RR, FUNDACEP 55 RR e CEPS $06031 \mathrm{RR}$, totalizando oito tratamentos. Para a coleta das amostras foi utilizada uma pá de corte que foi lavada com água e desinfestada com hipoclorito de sódio $1 \%$ e etanol $70 \%$, entre as repetições.

Para o isolamento de Fusarium spp., as raízes principais foram primeiramente lavadas em água corrente e desinfestadas em hipoclorito de sódio a $1 \%$ por 1 min, etanol $70 \%$ por 1 min e lavadas em água destilada esterilizada por três vezes seguidas. Posteriormente, as raízes foram colocadas em caixas do tipo Gerbox, com papel filtro esterilizado e umedecido, e incubadas durante $48 \mathrm{~h}$ a $25^{\circ} \mathrm{C}$, sob fotoperíodo de $12 \mathrm{~h}$, em incubadora do tipo BOD. Para o isolamento, estruturas reprodutivas de Fusarium spp. foram removidas com auxílio de alças esterilizadas para meio de cultura BatataDextrose-Ágar (BDA, extrato de $200 \mathrm{~g}$ de batata, $20 \mathrm{~g}$ de dextrose, $20 \mathrm{~g}$ de ágar e $1000 \mathrm{~mL}$ água destilada), para obtenção de culturas puras e posterior identificação.

Além disso, foram feitas diluições seriais do solo rizosférico para a quantificação de Unidades Formadoras de Colônia (UFCs) de Fusarium spp. e Trichoderma spp. As amostras de solo das quatro plantas coletadas foram reunidas, formando uma amostra composta, e $5 \mathrm{~g}$ de solo de cada tratamento 
foram diluídos em $95 \mathrm{~mL}$ de água destilada esterilizada, acrescida de duas gotas de Tween $80^{\mathrm{TM}}$ (Merck, Germany). Os frascos contendo a suspensão foram colocados em agitador do tipo Fisher - Flexa $\mathrm{Mix}^{\mathrm{TM}}$ (USA) por 10 minutos e, a partir dessa, foram feitas diluições seriais até o fator $10^{-4}$. Em seguida, $0,5 \mathrm{~mL}$ dessas diluições foram inoculados, em quatro placas de Petri, contendo $15 \mathrm{~mL}$ de meio BDA, acrescido de $0,05 \mathrm{mg}$ de estreptomicina/100 $\mathrm{mL}$ de meio de cultura, e incubadas por 5 dias a 25 ${ }^{\circ} \mathrm{C}$ e fotoperíodo de $12 \mathrm{~h}$ em incubadora do tipo BOD.

A contagem das colônias de Fusarium spp. e Trichoderma spp. foi feita sobre o fator de diluição serial $10^{-3}$, por meio de observação visual das colônias com base em bibliografia especializada (BARNETT; HUNTER, 1999). O número de UFCs de Fusarium spp. e Trichoderma spp. foi determinado de acordo com equações propostas por Carter (1993). Após a contagem de UFCs, foi realizada a identificação dos gêneros Fusarium e Trichoderma através da visualização de estruturas reprodutivas em microscópio ótico. As colônias de Trichoderma morfologicamente diferentes foram repicadas para meio de cultura BDA para posterior identificação baseada em métodos moleculares e utilização no teste de confrontação direta, no qual sua ação antagônica foi avaliada contra isolados de Fusarium. Culturas monospóricas foram obtidas para Trichoderma conforme a técnica de cultura monospórica descrita por Fernandes (1993) e, em seguida, foram cultivadas em meio BDA. Para sua manutenção, discos de micélio ( $5 \mathrm{~mm}$ de diâmetro) foram colocados em microtubos esterilizados e armazenados sob refrigeração $\left(4^{\circ} \mathrm{C}\right)$ até o momento de sua utilização.

Para a identificação de Fusarium spp. por meio de caracteres morfológicos, as colônias do fungo obtidas a partir de diluições de solo foram purificadas conforme a técnica de cultura monospórica descrita por Fernandes (1993), em que fragmentos do micélio dos fungos foram colocados em $5 \mathrm{~mL}$ de água destilada e esterilizada, agitados e plaqueados em placas de Petri contendo meio de cultura ÁgarÁgua (AA, 20 g de ágar e 1000 mL água destilada). Após 24 h de incubação em temperatura ambiente, foi realizada a observação dos conídios germinados em meio AA, através de microscópio ótico. Os conídios que germinaram isoladamente foram repicados para tubos de ensaio contendo meio de cultura BDA (para observação da cor e mensuração da colônia), e para placas de Petri contendo meio de cultura Folha de Cravo-Ágar (CLA, 20 g de ágar, $1000 \mathrm{~mL}$ de água destilada e 3 pedaços de folhas de cravo, Dianthus caryophyllus L., esterilizadas à 60 ${ }^{\circ} \mathrm{C} / 72 \mathrm{~h}$ ), que permitiu a melhor caracterização de macroconídios, microconídios e clamidósporos. O material foi incubado a $25{ }^{\circ} \mathrm{C}$ e fotoperíodo de 12 h durante 10-14 dias. Após esse período, realizouse a observação das microestruturas do fungo em microscópio estereoscópico e ótico e procedeu-se a identificação das espécies de acordo com chaves de classificação propostas por Gerlach e Nirenberg (1982), Nelson, Tousson e Marasas (1983) e Leslie e Summerell (2006).

Para avaliar o possível antagonismo de Trichoderma, foi realizado o teste de confrontação direta in vitro. Para isso, foram utilizados 12 isolados de Trichoderma e nove isolados de Fusarium obtidos na etapa acima descrita. Um disco de meio de cultura BDA com $12 \mathrm{~mm}$ de diâmetro, contendo micélio de Fusarium, foi transferido para placas de Petri (9,0 cm de diâmetro), também contendo $15 \mathrm{~mL}$ de meio BDA, e colocado a $0,5 \mathrm{~cm}$ da borda da placa. As placas foram incubadas por $48 \mathrm{~h}$ a $25 \pm 2{ }^{\circ} \mathrm{C}$ com fotoperíodo de $12 \mathrm{~h}$ em incubadora do tipo BOD. Após esse período, um disco de meio de cultura BDA, também com $12 \mathrm{~mm}$ de diâmetro, contendo micélio de Trichoderma, foi transferido para a posição oposta ao disco de micélio de Fusarium nas placas de Petri (a $0,5 \mathrm{~cm}$ da borda da placa). As placas foram incubadas durante 7 dias a $25 \pm 2{ }^{\circ} \mathrm{C}$ com fotoperíodo de $12 \mathrm{~h}$ (CARVALHO et al., 2011). Decorrido esse tempo, as placas foram avaliadas de acordo com o critério de Bell, Wells e Markham (1982), baseado em uma escala de notas variando 
de 1 a 5, na qual em 1 - Trichoderma cresce e ocupa toda a placa; 2 - Trichoderma cresce e ocupa uma parte do patógeno (Fusarium) (2/3 da placa); 3 - Trichoderma e Fusarium crescem até a metade da placa (nenhum domina o outro); 4 - Fusarium cresce e ocupa uma parte do Trichoderma (2/3 da placa); e em 5 - Fusarium cresce e ocupa toda a placa de Petri. Em seguida, as notas do antagonista foram agrupadas em classes (CARVALHO et al., 2011).

Os isolados de Trichoderma obtidos de solo rizosférico de soja com e sem sintomas de SMS, cujo desempenho foi mais eficiente em teste de confrontação direta, foram caracterizados por métodos moleculares. Tais isolados receberam os seguintes códigos de identificação: T53d, T55d, T002dA, T002dB, T031d, T006s, T005s e T002sB, em que: "d" representa isolado de planta doente e "s" isolado de planta sadia; "A"e "B" indicam isolados morfologicamente diferentes obtidos de um mesmo genótipo de soja. Para o estudo molecular desses isolados, os mesmos foram cultivados em meio de cultura Caldo Batata (extrato de $200 \mathrm{~g}$ de batata, 20 $\mathrm{g}$ de dextrose e $1000 \mathrm{~mL}$ água destilada) por 10 dias, a $25{ }^{\circ} \mathrm{C}$ com fotoperíodo de $12 \mathrm{~h}$. A extração de DNA foi realizada a partir do micélio, de acordo com o protocolo de Doyle e Doyle (1990). Nas reações de PCR, foram utilizados os oligonucleotídeos iniciadores ITS 1 e ITS 4 (WHITE et al., 1990). A reação totalizou $25 \mu \mathrm{L}$ contendo aproximadamente

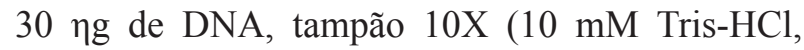
pH 8,3; $50 \mathrm{mM} \mathrm{KCl} ; 0,1 \%$ de tween $10 ; 2,5 \mathrm{mM}$ $\mathrm{MgCl}_{2}$ ), 2,5 $\mu \mathrm{M}$ de cada dNTP, $20 \mathrm{nM}$ de $\mathrm{MgCl}_{2}$, 25 ๆmoles de cada um dos oligonucleotídeos iniciadores (Biogen), $5 \mathrm{U}$ da enzima Taq DNA polimerase (Invitrogen ${ }^{\mathrm{TM}}$ Life Technologies) e água ultrapura para completar o volume da reação. As reações foram realizadas em termociclador $\mathrm{MJ}$ Research, INC. PTC - 100MT, sob as seguintes condições térmicas: $94{ }^{\circ} \mathrm{C}$ por $2 \mathrm{~min} ; 30$ ciclos de $94{ }^{\circ} \mathrm{C}$ por $45 \mathrm{~s} ; 55^{\circ} \mathrm{C}$ por $30 \mathrm{~s} ; 72{ }^{\circ} \mathrm{C}$ por $35 \mathrm{~s} \mathrm{e} 72$
${ }^{\circ} \mathrm{C}$ por $10 \mathrm{~min}$. Ao final da reação, o produto foi mantido a $-4{ }^{\circ} \mathrm{C}$. Um controle negativo, sem DNA, foi incluído nas amplificações do PCR. Os produtos da PCR foram purificados com PEG 8000 13\% e, nas reações de sequenciamento, utilizaram-se os oligonucleotídeos ITS1 e ITS4. Para estas reações, foi seguido o protocolo fornecido pelo fabricante (Biogen).

Os fragmentos sequenciados foram analisados e comparados com sequências já existentes através da ferramenta BLAST, contra a base de dados do GenBank, sediado no National Center for Biotechnology Information (NCBI) (http://www. ncbi.nlm.nih.gov/) (ALTSCHUL et al., 1997), a fim de comparar similaridades com outras espécies de Trichoderma. As sequências do GenBank que apresentaram as melhores coberturas e os maiores escores de similaridade foram selecionadas e alinhadas juntamente com as sequências obtidas no sequenciamento pelo algoritmo CLUSTAL W (THOMPSON; HIGGINS; GIBSON, 1994). A análise filogenética foi conduzida utilizandose o método de Máxima Verossimilhança com 5000 replicatas pelo programa MEGA versão 5 (TAMURA et al., 2007). Para construção dos dendrogramas, foram utilizadas as sequências de Trichoderma spp. apresentadas na Tabela 1 .

$\mathrm{O}$ delineamento experimental utilizado foi $\mathrm{o}$ inteiramente casualizado com quatro repetições por tratamento. Devido ao fato dos dados não seguirem uma distribuição normal, foram empregados testes não-paramétricos. Assim, os valores estimados em Unidades Formadoras de Colônias (UFCs) por grama de solo rizosférico foram submetidos à análise da variância pelo teste de comparações múltiplas de Kruskal-Wallis (SIEGEL; CASTELLAN, 2006). Para o teste de confrontação direta, a comparação entre as notas atribuídas a cada isolado foi feita através do Teste U de Mann-Whitney. Essas análises foram feitas com auxílio do programa estatístico STATISTICA 7.0. 
Tabela 1. Códigos de acesso no GenBank para os isolados de Trichoderma spp. (região ITS) utilizados neste estudo. Santa Maria, RS, 2013.

\begin{tabular}{cccc}
\hline Origem & \multicolumn{1}{c}{ Isolado } & $\begin{array}{c}\text { Código de } \\
\text { acesso }\end{array}$ & Referência \\
\hline Nova Zelândia & T. dorotheae GJS 99-97 & DQ333547 & Samuels et al. (2005) \\
Brasil & Trichoderma sp.T002dB & KC481705 & Milanesi et al. (2013) \\
Nova Zelândia & T. dorotheae GJS 99-202 & DQ313144 & Samuels et al. (2006) \\
Nova Zelândia & T. dorotheae GJS 99-202 & DQ313145 & Samuels et al. (2006) \\
Austrália & T. dorotheae GJS 99-194 & DQ313136 & Samuels et al. (2006) \\
Equador & T. ovalisporum Dis 70a & AY380897 & Holmes et al. (2004) \\
Brasil & T. ovalisporum Dis 172h & AY380896 & Holmes et al. (2004) \\
China & T. koningii CCRC33566 & AF414312 & Lee; Hseu (2002) \\
China & T. koningii CCRC33563 & AF414310 & Lee; Hseu (2002) \\
Nova Zelândia & T. koningii & AF055211 & Dodd et al. (2000) \\
Índia & T. koningiopsis IBSD-GF6 & KC428393 & Devi (2012) \\
Brasil & T. koningiopsis UFSM-Tr3s & KC155358 & Milanesi et al. (2012) \\
Brasil & Trichoderma sp.T53d & KC481709 & Milanesi et al. (2013) \\
Brasil & Trichoderma sp.T005s & KC481707 & Milanesi et al. (2013) \\
Brasil & Trichoderma sp.T002sB & KC481706 & Milanesi et al. (2013) \\
Brasil & Trichoderma sp.T006s & KC481708 & Milanesi et al. (2013) \\
Brasil & Trichoderma sp.T002dA & KC481704 & Milanesi et al. (2013) \\
China & Hypocrea koningii PKU F2 & KC113283 & Singh et al. (2012) \\
Índia & T. koningiopsis NBAII(N)KA 8A-Tk & GU479416 & Roopa et al. (2010) \\
China & T. harzianum A14 & KC139307 & Yao (2012) \\
China & T. harzianum A12 & KC139308 & Yao (2012) \\
Brasil & T. harzianum UFMGCB 3518 & JQ418366 & de Faria et al. (2011) \\
Brasil & T. harzianum UFMGCB 3517 & JQ418474 & de Faria et al. (2011) \\
Estados Unidos & Fusarium oxysporum 0531 & EF464166 & Zhang et al. (2007) \\
\hline
\end{tabular}

Fonte: Elaboração dos autores. Adaptado de: National Center for Biotechnology Information. Disponível em: <http://www.ncbi. nlm.nih.gov/>.

\section{Resultados e Discussão}

A análise comparativa da ocorrência de fungos do gênero Fusarium e Trichoderma entre genótipos de soja foi realizada separadamente para plantas com e sem sintomas de Síndrome da Morte Súbita. Houve diferença significativa no número de unidades formadoras de colônias de Trichoderma entre genótipos, tanto em plantas com sintomas como sem sintomas de SMS. Entretanto, para
Fusarium verificou-se diferença significativa apenas em plantas sem sintomas da doença (Figura 1). As maiores médias para a população de Fusarium, em plantas sem sintomas, foram encontradas nos genótipos CEPS 06031 RR, CEPS 06005 RR e CEPS 06006 RR. O menor número de unidades formadoras de colônias de Fusarium foi observado a partir de amostras do genótipo CEPS 06015 RR em solo rizosférico. 
Figura 1. População de Fusarium spp. em solo rizosférico de genótipos de soja,com e sem sintomas de Síndrome da Morte Súbita (SMS), em sistema plantio direto. Médias seguidas pela mesma letra não diferem estatisticamente pelo teste de Kruskal-Wallis. Santa Maria, RS. 2007.

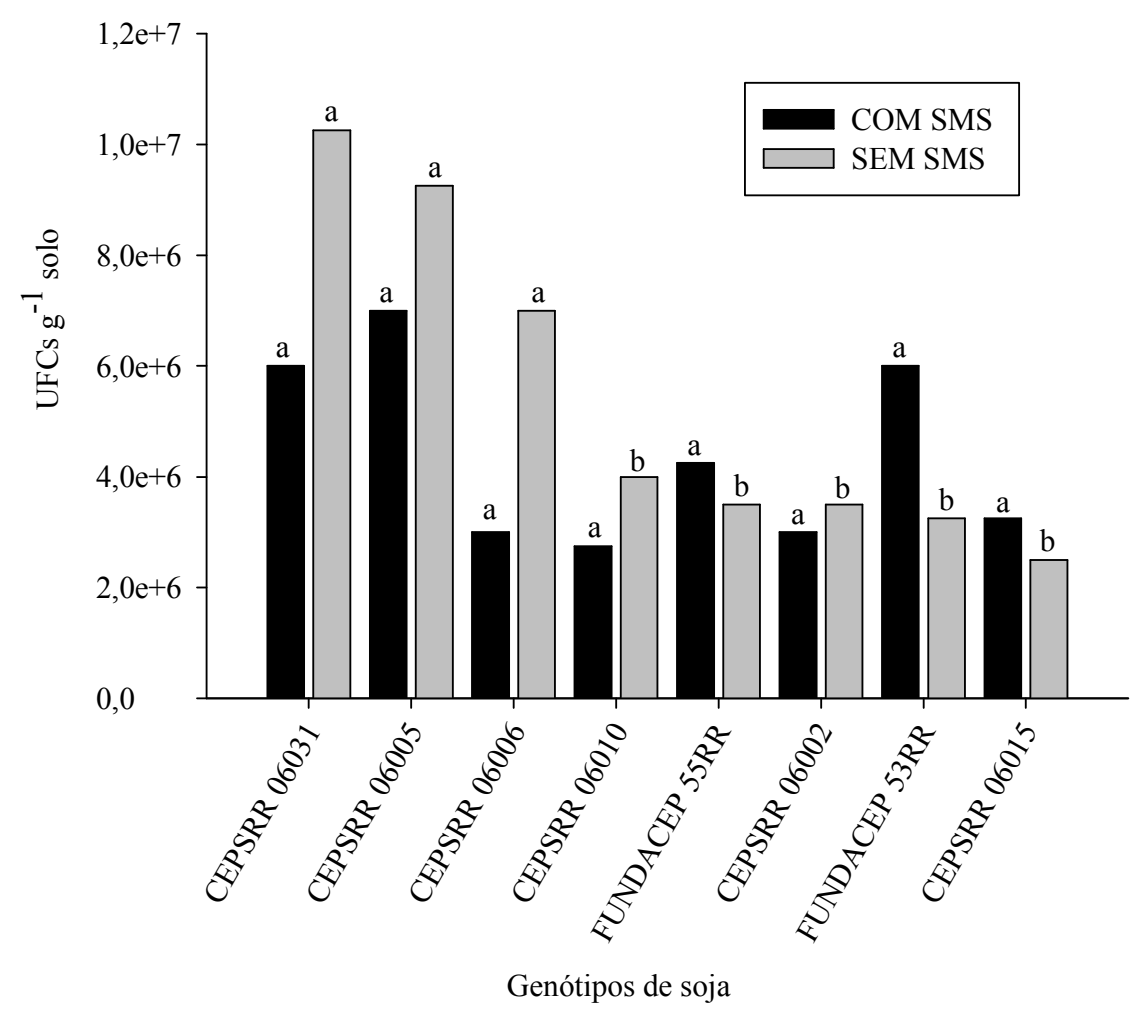

Fonte: Elaboração dos autores.

As variações que ocorrem na comunidade microbiana da rizosfera são dependentes do tipo de solo, espécie vegetal e cultivar utilizada, visto que estas produzem exsudatos ricos em determinados compostos mais favoráveis a alguns grupos de micro-organismos rizosféricos. Algumas substâncias presentes na rizosfera podem atuar como alelopáticas, inibindo ou estimulando esses indivíduos, entre outras cuja ação pode ser de sinalização molecular a fim de estabeleceremse simbioses mutualísticas ou parasíticas entre os micro-organismos e as plantas. Estas relações influenciam também as populações de antagonistas existentes nesse ambiente (MOREIRA; SIQUEIRA, 2006). Nesse sentido, a diferença nas populações de Fusarium entre os genótipos de soja sem sintomas de SMS pode estar relacionada à produção desses exsudatos que seriam mais favoráveis à multiplicação de algumas espécies do patógeno do que para outras, mas sem capacidade de infecção. Além disso, também pode ter havido uma pressão de seleção entre espécies melhor adaptadas e com maior competência em rizosfera para se estabelecer e colonizar a porção radicular de determinados genótipos. Para a supressão do patógeno, fatores como teor de matéria orgânica do solo, processos de decomposição e ciclagem de nutrientes, tipo de solo e de agente patogênico, estação de cultivo e tipo de planta cultivada possuem interferência direta (TERMORSHUIZEN et al., 2006).

Com relação à Trichoderma, observou-se que o maior número de isolados foi obtido a partir do genótipo CEPS 06006 RR, seguido do genótipo CEPS 06002 RR, independentemente da presença 
ou não de sintomas de SMS nas plantas (Figura 2). Nos genótipos CEPS 06015 RR e FUNDACEP 55 RR também foi observado maior número de unidades formadoras de colônias de Trichoderma em amostras de solo coletadas em plantas com SMS. Por outro lado, o genótipo FUNDACEP 55 RR não apresentou isolados de Fusarium spp. proveniente de raízes (Tabela 2), o que poderia estar relacionado à elevada densidade populacional de Trichoderma spp. na rizosfera das plantas de soja com sintomas de Síndrome da Morte Súbita. As amostras oriundas do genótipo FUNDACEP 53 RR, com SMS, mostraram diminuição significativa do número de unidades formadoras de colônias de Trichoderma. Neste trabalho, fungos do gênero Trichoderma estiveram associados ao solo rizosférico de soja, tanto em plantas com e sem sintomas de SMS, sendo capazes de se estabelecerem também em um ambiente em que ocorre a predominância do patógeno.

Tabela 2. Espécies de Fusarium associadas ao sistema radicular de genótipos de soja, com sintomas de Síndrome da Morte Súbita (SMS), em sistema plantio direto. Santa Maria, RS, 2008.

\begin{tabular}{ccl}
\hline Código de identificação & Genótipo de soja & \multicolumn{1}{c}{ Espécies e descritores } \\
\hline F001d & FUNDACEP 53 RR & F. avenaceum (Fr.) Sacc. 1886 \\
F002d & CEPS 06002 RR & F. solani (Mart.) Sacc. 1881 \\
F010dA & CEPS 06010 RR & F. oxysporum Schlecht. \\
F010dB & CEPS 06010 RR & F. solani (Mart.) Sacc. 1881 \\
F031d & CEPS 06031 RR & F. graminearum Schwabe 1839 \\
F005d & CEPS 06005 RR & F. verticillioides J. Sheld. 1904 \\
F006dA & CEPS 06006 RR & F. solani (Mart.) Sacc. 1881 \\
F006dB & CEPS 06006 RR & F. solani (Mart.) Sacc. 1881 \\
F015d & CEPS 06015 RR & F. solani (Mart.) Sacc. 1881 \\
\hline
\end{tabular}

${ }^{(1)}$ F: Fusarium spp.; F : nome do genótipo de soja do qual o isolado foi obtido; d: isolado de solo rizosférico de plantas com sintomas da doença; A ou B: isolados morfologicamente diferentes de um mesmo genótipo.

Fonte: Elaboração dos autores.

Quando a planta de soja é atacada por Fusarium solani f. sp. glycines, as raízes produzem quantidades suficientes de gliceolina, uma fitoalexina que atua em resposta à infecção pelo patógeno. Este pode ser um fator importante no fornecimento de resistência parcial a esse fungo e varia conforme o genótipo de soja (LOZOVAYA et al., 2006). Diferenças na composição dos exsudatos radiculares liberados pelas plantas condicionariam, beneficiando ou prejudicando, a composição microbiana da rizosfera (AIRA et al., 2010). $\mathrm{Na}$ área em que foram realizadas as coletas das amostras utilizadas no presente trabalho, a rotação de culturas incluía soja/milho durante o verão, e azevém ou trigo nos meses de inverno. Essas rotações, ou algumas delas, podem ter influenciado as populações do patógeno e do antagonista, beneficiando-as ou prejudicando-as. 
Figura 2. População de Trichoderma spp. em solo rizosférico de genótipos de soja, com e sem sintomas de Síndrome da Morte Súbita (SMS), em sistema plantio direto. Médias seguidas pela mesma letra não diferem estatisticamente pelo teste de Kruskal-Wallis. Santa Maria, RS. 2007.

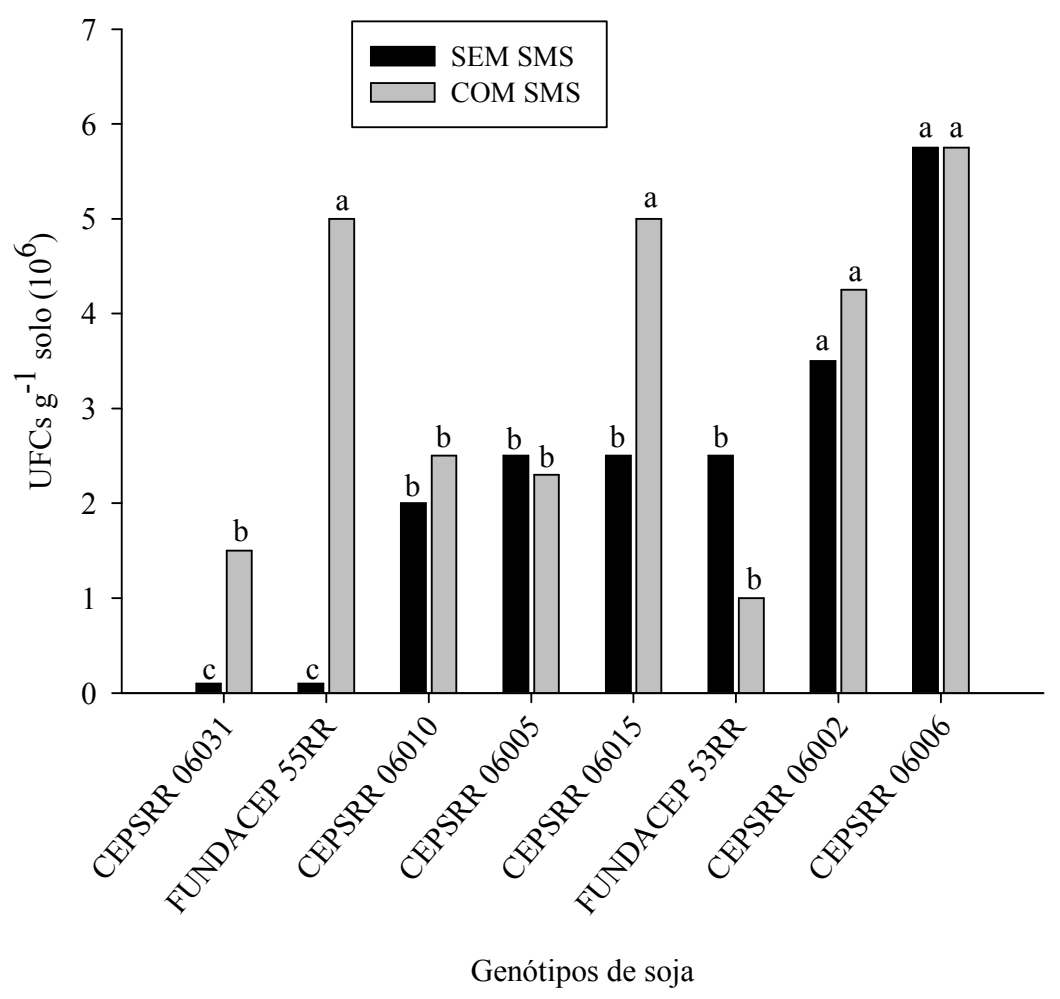

Fonte: Elaboração dos autores.

Entre os isolados de Fusarium, foram identificadas morfologicamente nove espécies obtidas de raízes de plantas com SMS e os resultados encontram-se na Tabela 2. Embora outras espécies tenham sido identificadas, $F$. solani foi a mais evidente, o que indicaria grande possibilidade de ocorrência de SMS, em safras seguintes, na área em que as amostras foram coletadas. As espécies $F$. avenaceum e $F$. graminearum, poderiam ser remanescentes da cultura anterior (restos culturais), já que essa área foi cultivada com trigo e/ou azevém durante o inverno.

Com relação à seleção de isolados de Trichoderma com potencial antagônico a Fusarium houve diferença significativa entre os advindos de plantas com e sem SMS, somente para quatro isolados do patógeno (Tabela 3). Os isolados F010dA e F005d de Fusarium, confrontados com Trichoderma de plantas sem sintomas de SMS, e os isolados F010dB e F006dA, confrontados com Trichoderma de plantas com SMS, foram mais sensíveis ao antagonista, com notas no teste de confrontação direta mais próximas a 1 . Os relatos de que haveria uma pressão de seleção do meio (planta doente) sobre a eficiência do antagonismo se comprovaram neste trabalho, pois os antagonistas mais eficazes foram aqueles associados à rizosfera de plantas com sintomas da doença, controlando três (T53d, T55d) ou quatro (T002dA, T002dB e T031d) isolados de Fusarium (Tabela 4).

Esses seis isolados de Trichoderma foram submetidos à análise da região ITS1-5.8S-ITS2 e, 
após a comparação com sequências depositadas no GenBank, verificou-se que todos tiveram similaridade com espécies do agregado T. koningii, fornecendo indícios de que os isolados sequenciados possam pertencer a alguma dessas espécies (Tabela 1 e Figura 3). Isso pode ser observado através de um elevado suporte de bootstrap (igual a 100) entre o clado formado pelo agregado T. koningii e o clado T. harzianum.

Tabela 3. Classes de antagonismo (médias das notas) do teste de confrontação direta obtidas pelos isolados de Trichoderma sp., oriundos de solo rizosférico de soja com e sem sintomas de Síndrome da Morte Súbita (SMS), em função de isolados de Fusarium spp. Santa Maria, RS, 2008.

\begin{tabular}{|c|c|c|c|}
\hline \multirow{2}{*}{ Fusarium spp. $^{(1)}$} & \multicolumn{2}{|c|}{ Classes de antagonismo de Trichoderma sp. $^{(2)}$} & \multirow{2}{*}{ Nível de $p^{* *}$} \\
\hline & Plantas com SMS & Plantas sem SMS & \\
\hline F001d & 1,78 & 2,00 & $0,16^{\mathrm{ns}}$ \\
\hline F002d & 1,65 & 1,62 & $0,76^{\mathrm{ns}}$ \\
\hline F010dA & 2,06 & 1,08 & $0,00^{*}$ \\
\hline F010dB & 1,50 & 2,75 & $0,00^{*}$ \\
\hline F031d & 2,93 & 3,12 & $0,67^{\mathrm{ns}}$ \\
\hline F005d & 2,34 & 1,75 & $0,04^{*}$ \\
\hline F006dA & 1,62 & 2,00 & $0,03^{*}$ \\
\hline F006dB & 1,75 & 1,87 & $0,36^{\mathrm{ns}}$ \\
\hline F015d & 1,53 & 1,83 & $0,11^{\mathrm{ns}}$ \\
\hline
\end{tabular}

${ }^{(1)} \mathrm{F}$ : Fusarium spp.; F : nome do genótipo de soja do qual o isolado foi obtido; d: isolado de solo rizosférico de plantas com sintomas da doença; $\mathrm{A}$ ou B: isolados morfologicamente diferentes de um mesmo genótipo. ${ }^{(2)}$ Classes de antagonismo (adaptado de CARVALHO et al., 2011). Classe 1: Trichoderma spp. cresce sobre o patógeno e ocupa toda a superfície do meio; classe 2: Trichoderma spp. cresce sobre pelo menos 2/3 da superfície do meio; classe 3: Trichoderma spp. ocupa aproximadamente a metade da superfície do meio; classe 4: Trichoderma spp. cresce sobre 1/3 do meio; e classe 5: Trichoderma spp. não cresce e o patógeno ocupa toda a superfície da placa (BELL; WELLS; MARKHAM, 1982); ( ${ }^{*}$ ) significativo; ( ${ }^{\text {ns }}$ ) não significativo pelo Teste U de Mann-Whitney. $\left(p^{* *}\right)$ Probabilidade de erro $(p<0,05)$.

Fonte: Elaboração dos autores.

Tabela 4. Isolados de Trichoderma sp. mais competitivos no teste de confrontação direta (classe de antagonismo 1) frente a isolados de Fusarium spp. de plantas com Síndrome da Morte Súbita (SMS). Santa Maria, RS, 2008.

Isolados de Trichoderma $\mathbf{s p .}{ }^{*}$
T53d
T55d
T002dA
T002dB
T031d
T006s
T005s
T002sB

\author{
Isolados de Fusarium spp." controlados \\ F010dB, F006dA e F015d \\ F010dB, F006dA e F002d \\ F001dA, F010dB, F002d e F015d \\ F010dB, F002d, F015d e F001d \\ F010dB, F00d2, F015d e F001dA \\ F010dA \\ F005d \\ F010dA
}

$\left(^{*}\right)$ Isolados seguidos pelas letras T: Trichoderma sp. e F: Fusarium spp; $\mathrm{T}_{\text {_ }}$ e F_ _ nome do genótipo de soja do qual o isolado foi obtido; "d" ou "s": isolado de solo rizosférico de plantas com ou sem sintomas da doença; "A" ou "B": isolados morfologicamente diferentes obtidos de um mesmo genótipo.

Fonte: Elaboração dos autores. 
Figura 3. Dendograma filogenético baseado no método de "Neighbor-Joining" derivado das sequências das regiões ITS1-5.8S-ITS2 do rDNA amplificadas pelos oligonucleotídeos ITS1 e ITS4, com base em 1000 réplicas de "bootstrap", para isolados de Trichoderma sp.: T53d, T005s, T002sB, T006s, T002dA e T002dB. As sequências obtidas e utilizadas nesse estudo, com seus respectivos números de acesso no GenBank, estão listadas na Tabela 1. O número nas ramificações representa o número de "bootstrap". Fusarium oxysporum (EF464166) foi utilizado como outgroup. Santa Maria, 2013.

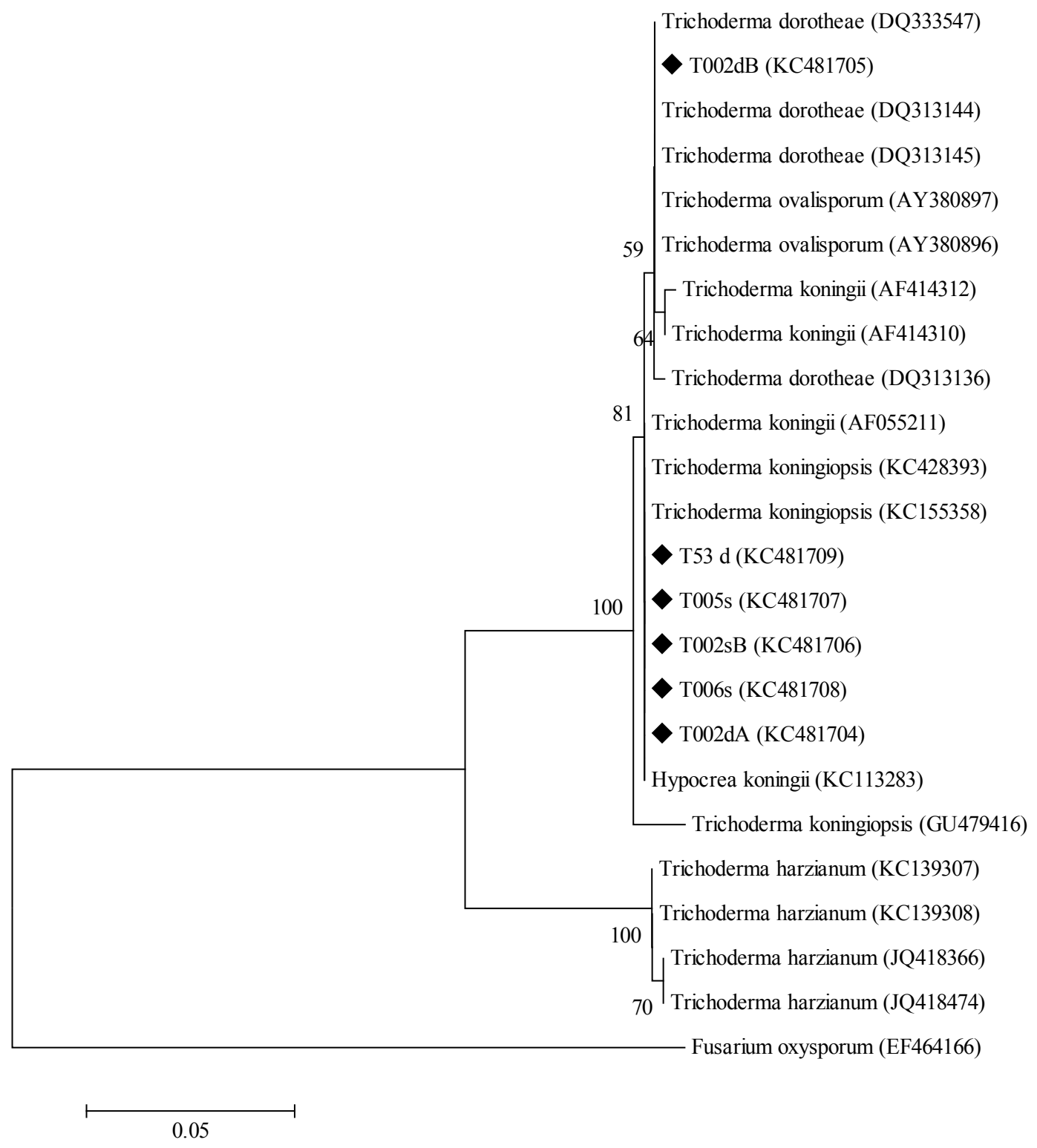

Fonte: Elaboração dos autores.

Contrariamente, os isolados T006s, T005s e T002sB, oriundos de plantas sem SMS, foram eficazes no controle de apenas um isolado de Fusarium cada (F010dA e F005d). Estes resultados revelam que a bioprospecção de isolados de Trichoderma antagonistas a Fusarium em locais onde há proliferação da doença pode ser uma estratégia promissora, pois pode levar à obtenção de 
novas linhagens mais competitivas contra agentes patogênicos.

As espécies de Trichoderma podem sobreviver a expensas de carboidratos complexos liberados pela degradação de outros fungos, além da produção de enzimas e antibióticos, expressão de proteínas e biocontrole de fitopatógenos (BENÍTEZ et al., 2004). Nesse sentido, é possível que os isolados de Trichoderma sp. avaliados nesse estudo induzam a produção de enzimas quitinolíticas e endoglucanases em células do sistema radicular do hospedeiro, compostos estes também associados ao seu micoparasitismo (ALMEIDA et al., 2007; GAJERA; VAKHARIA, 2010). T. koningiopsis, apesar de ser considerado cosmopolita, é mais comum em latitudes de clima tropical do que clima temperado, pois frequentemente são obtidos isolados dessa espécie como endofíticos em Theobroma spp. Também constitui uma espécie agregada a T. koningii Oudem. 1902, com potencial para o controle biológico de diversos patógenos (SAMUELS et al., 2006).

Assim como outras espécies de Trichoderma, $T$. koningii beneficia a sanidade da planta e pode atuar na biomineralização de cristais de cálcio no solo (OYARBIDE; OSTERRIETH; CABELLO, 2001). Dal Soglio et al. (1998) observaram a presença de enzimas quitinolíticas ao avaliarem o efeito de tratamentos compostos por filtrados de cultura de T. harzianum Rifai 1969, isolado Th008, aplicados em sementes de soja, inoculadas com um isolado de Rhizoctonia solani. Os autores evidenciaram a presença de três enzimas quitinolíticas na rizosfera das plântulas de soja 15 dias após a emergência.

Uma das características atreladas ao controle biológico que Trichoderma spp. possuem é a produção de enzimas líticas extracelulares que degradam a parede celular de outros fungos. Além disso, indivíduos desse gênero são importantes na ciclagem de nutrientes e, em alguns casos, vêm sendo utilizados para a produção de celulase em escala comercial (CORABI-ADELL; LUCON;
KOIKE, 2002). As interações antagonísticas desenvolvidas na rizosfera melhoram o crescimento das plantas (HOYOS-CARVAJAL; ORDUZ; BISSETT, 2009) e a sanidade das mesmas, colaborando para a manutenção da qualidade do solo e dos agroecossistemas (BAREA; AZCÓN; AZCÓN-AGUILAR, 2002), já que a competência de rizosfera é uma característica importante para a seleção de agentes de controle biológico (HARMAN et al., 2004).

Esse resultado pode indicar alta capacidade antagônica aos isolados de Fusarium avaliados e aponta que os isolados de Trichoderma sp. testados podem apresentar um elevado potencial para utilização em um manejo integrado de doenças radiculares na cultura da soja. Além disso, esse estudo também demonstrou que Trichoderma sp. poderia apresentar um caráter agressivo, sendo capaz de se estabelecer em um dado ambiente (mesmo com uma maior pressão do patógeno, conforme os resultados acima apresentados), desde que dadas às condições apropriadas para tal, prevalecendo sobre outras espécies.

Os isolados de Fusarium F010dA (F. oxysporum), F015d (F. solani), F002d (F. solani) e F001d ( $F$. avenaceum) foram os que tiveram um maior número de isolados de Trichoderma sp. capazes de controlá-los, indicando que esses isolados do patógeno poderiam ser mais sensíveis à ação do antagonista. Também não pode ser desconsiderado o fato de que essas espécies de Fusarium não seriam tão agressivas. Ethur et al. (2005), avaliando fungos antagonistas a Sclerotinia sclerotiorum (Lib.) de Bary 1884, relataram que além da variabilidade entre isolados de Trichoderma pode-se encontrar também diferenças na ação desses dependendo da temperatura, umidade e tipo de solo.

Selecionando isolados de Trichoderma spp. para o controle de Sclerotium rolfsii Sacc. em soja, Lohmann et al. (2007) observaram que os isolados I, II e III do antagonista, oriundos de três amostras de solo coletadas em diferentes áreas, apresentaram 
efeito controlador sobre o patógeno, provocando menor incidência de damping off em plântulas de soja. Além disso, a contagem de conídios dos isolados de Trichoderma spp. I e II foi maior quando comparada ao isolado III, sendo os primeiros mais agressivos e capazes de dominar o ambiente, controlando o fitopatógeno.

Os isolados de Trichoderma spp. T53d, T55d, T002dA, T002dB e T031d, oriundos de solo rizosférico de genótipos de soja com sintomas de SMS, apresentaram maior capacidade antagônica aos isolados de Fusarium spp. testados. Em comparação com outros autores, foi observado que os isolados de Trichoderma sp. que obtiveram nota 1 no teste de confrontação direta foram mais competentes em se estabelecer na rizosfera dos genótipos de soja estudados e poderiam ter atuado sobre as condições ambientais do solo, modificando-as, disputando nutrientes e espaço com o fitopatógeno.

É importante ressaltar que ainda há uma carência de respostas acerca das interações entre antagonistas e o patossistema soja-SMS, visto que a utilização do controle biológico de doenças, compondo um manejo integrado, atrai considerável interesse de produtores rurais e empresas, que integram um nicho de mercado voltado à sustentabilidade na agricultura. A realização de testes em casade-vegetação e a seleção de novos isolados de Trichoderma sp., entre outras espécies do fungo, juntamente com estudos de sua variabilidade genética, enfatiza a importância pela busca de novas perspectivas para emprego do controle biológico no manejo de SMS e outras doenças causadas por patógenos de solo na soja.

\section{Conclusões}

Nos genótipos de soja CEPS 06006 RR, CEPS 06002 RR, FUNDACEP 53 RR, CEPS 06010 RR, CEPS 06005 RR, CEPS 06015 RR, FUNDACEP 55 RR e CEPS 06031 RR, a população de Fusarium spp. em solo rizosférico difere em quantidade apenas entre genótipos sem sintomas de Síndrome da Morte Súbita e Trichoderma spp. está associado ao solo rizosférico em soja, tanto em plantas sem sintomas de Síndrome da Morte Súbita quanto em plantas com sintomas da doença, em quantidades diferentes nos diferentes genótipos estudados.

Os isolados de Trichoderma spp. T55d e Trichoderma sp. T53d, T002dA, T002dB e T031d, de solo rizosférico de genótipos de soja com sintomas de Síndrome da Morte Súbita, apresentam maior capacidade antagônica a Fusarium spp. e podem ser utilizados em testes a campo, envolvendo os genótipos das quais foram obtidos, entre outros, a fim de verificar se o antagonismo é mantido e buscar o controle biológico da doença.

\section{Agradecimentos}

Os autores agradecem à Coordenação de Aperfeiçoamento de Pessoal de Ensino Superior (CAPES) pela concessão de bolsas de estudo; à FUNDACEP/CCGL por viabilizar a coleta de solo em sua área experimental; e aos revisores anônimos pelas importantes sugestões e correções.

\section{Referências}

AIRA, M.; GÓMEZ-BRANDÓN, M.; LAZCANO, C.; BÅÅTH, E.; DOMÍNGUEZ, J. Plant genotype strongly modifies the structure and growth of maize rhizosphere microbial communities. Soil Biology \& Biochemistry, Elmsford, v. 42, n. 12, p. 2276-2281, 2010.

ALMEIDA, F. B.; CERQUEIRA, F. M.; SILVA, R. N.; ULHOA, C. J. Mycoparasitism studies of Trichoderma harzianum strains against Rhizoctonia solani: evaluation of coiling and hydrolytic enzyme production. Biotechnology Letters, Netherlands, v. 29, n. 8, p. 11891193, 2007.

ALTSCHUL, S. F.; MADDEN, T. L.; SCHAFFON, A. A.; ZHANG, J.; ZHANG, Z.; MILLER, W.; LIPMAN, D. J. Gapped BLAST and PSI-BLAST: a new generation of protein data base search programs. Nucleic Acids Research, Bethesda, v. 73, n. 17, p. 3389-3402, 1997.

AOKI, T.; O'DONNELL, K.; SCANDIANI, M. M. 
Sudden death syndrome of soybean in South America is caused by four species of Fusarium: Fusarium brasiliense sp. nov., F. cuneirostrum sp. nov., F. tucumaniae and $F$. virguliforme. Mycoscience, Tokyo, v. 46, n. 3, p. 162183, 2005.

BAREA, J. M.; AZCÓN, R.; AZCÓN-AGUILAR, C. Mycorrhizosphere interactions to improve plant fitness and soil quality. Antonie van Leeuwenhoek, Dordrecht, v. 81, n. 1-4, p. 343-351, 2002.

BARNETT, H. L.; HUNTER, B. B. Ilustrated genera of imperfect fungi. 4. ed. Minnesota: American Phytopathology Society, 1999. 218 p.

BELL, D. K.; WELLS, H. D.; MARKHAM, C. R. In vitro antagonism of Trichoderma species against six fungal plant pathogens. Phytopathology, Saint Paul, v. 72, n. 4, p. 379-382, 1982.

BENÍTEZ, T.; RINCÓN, A. M.; LIMÓN, M. C.; CODÓN, A. C. Biocontrol mechanisms of Trichoderma strains. International Microbiology, Spanish, v. 7, n. 4, p. 249-260, 2004.

CARTER, M. R. Soil Sampling and Methods of Analysis. Boca Raton: CRC Press, 1993. 823 p.

CARVAlHO, D. D. C.; MELlO, S. C. M.; LOBO JÚNIOR, M.; SILVA, M. C. Controle de Fusarium oxysporum f.sp. phaseoli in vitro e em sementes, e promoção do crescimento inicial do feijoeiro comum por Trichoderma harzianum. Tropical Plant Pathology, Brasília, v. 36, n. 1, p. 28-34, 2011.

COOK, R. J. Making greater use of introduced microorganisms for biological control of plant pathogen. Annual Review of Phytopathology, Saint Paul, v. 31, n. 1, p. 53-80, 1993.

COMISSÃO DE QUÍMICA E FERTILIDADE DO SOLO - RS/SC - CQFS-RS/SC. Recomendações de adubação e calagem para os estados do Rio Grande do Sul e Santa Catarina. 3. ed. Passo Fundo: SBCS Núcleo Região Sul/ UFRGS, 2004. 400 p.

CORABI-ADELL, C.; LUCON, C. M. M.; KOIKE, C. M. Biodiversidade do gênero Trichoderma no estado de São Paulo - aspectos enzimáticos e potencial biocontrolador. Arquivos do Instituto Biológico, São Paulo, v. 69, p. 158191, 2002. Suplemento

DAL SOGLIO, F. K.; BERTAGNOLLI, B. L.; SINCLAIR, J. B.; YU, G. Y.; EASTBURN, D. M. Production of chitinolytic enzymes and endoglucanase in the soybean rhizosphere in the presence of Trichoderma harzianum and Rhizoctonia solani. Biological Control, Orlando, v. 12, n. 2, p. 111-117, 1998.

DOYLE, J. J.; DOYLE, J. L. Isolation of plant DNA from fresh tissue. Focus, Ithaca, v. 12, p. 13-18, 1990.

EMPRESA BRASILEIRA DE PESQUISA AGROPECUÁRIA - EMBRAPA. Centro nacional de pesquisa de solos. Ministério da agricultura e do abastecimento. Sistema brasileiro de classificação de solos. Brasília: EMBRAPA, 1999. 412 p.

ETHUR, L. Z.; BLUME, E.; MUNIZ, M.; DA SILVA, A. C. F.; STEFANELO, D. R.; DA ROCHA, E. K. Fungos antagonistas a Sclerotinia sclerotiorum em pepineiro cultivado em estufa. Fitopatologia brasileira, Brasília, v. 30 , n. 2, p. 127-133, 2005.

ETHUR, L. Z.; DA ROCHA, E. K.; MILANESI, P.; MUNIZ, M. F. B.; BLUME, E. Sanidade de sementes e emergência de plântulas de nabo forrageiro, aveia preta e centeio submetidas a tratamentos com bioprotetor e fungicida. Ciência e natura, Santa Maria, v. 28, n. 2, p. 17-27, 2006.

ETHUR, L. Z.; BLUME, E.; MUNIZ, M. F. B.; ANTONIOLLI, Z. I.; NICOLINI, C.; MILANESI, P.; FORTES, F. O. Presença dos gêneros Trichoderma e Fusarium em solo rizosférico e não-rizosférico cultivado com tomateiro e pepineiro, em horta e estufa. Ciência rural, Santa Maria, v. 38, n. 1, p. 19-26, 2008.

FEHR, W. R.; CAVINESS, C. E. Stages of soybean development (Special report, 80). Ames: State University of Science and Technology, 1977. $11 \mathrm{p}$.

FERNANDES, M. R. Manual para laboratório de fitopatologia. Passo Fundo: Embrapa-CNPT, 1993. 128 p.

FREITAS, T. M. Q.; MENEGHETTI, R. C.; BALARDIN, R. S. Dano devido à podridão vermelha da raiz na cultura da soja. Ciência rural, Santa Maria, v. 34, n. 4, p. 991996, 2004.

GAJERA, H. P.; VAKHARIA, D. N. Molecular and biochemical characterization of Trichoderma isolates inhibiting a phytopathogenic fungi Aspergillus niger Van Tieghem. Physiological and molecular plant pathology, United States, v. 74, n. 3-4, p. 274-282, 2010.

GERLACH, W.; NIRENBERG, H. The genus Fusarium: a pictorial atlas. Berlin: Biologische Bundesanstald für Land-und. Institut Für Mikrobiologie, 1982. 406 p.

GESHEVA, V. Rhizosphere microflora of some citrus as a source of antagonistic actinomycetes. European Journal of Soil Biology, Braunschweig, v. 38, n. 1, p. 8588, 2002.

HARMAN, G. E.; HOWELL, C. R.; VITERBO, 
A.; CHET, I.; LORITO, M. Trichoderma species opportunistic, avirulent plant symbionts. Nature Reviews Microbiology, London, v. 2, n. 1, p. 43-56, 2004.

HOWEL, C. R. Mechanisms employed by Trichoderma species in the biological control of plant diseases: the history and evolution of current concepts. Plant Disease, Saint Paul, v. 87, n. 1, p. 4-10, 2003.

HOYOS-CARVAJAL, L.; ORDUZ, S.; BISSETT, J. Growth stimulation in bean (Phaseolus vulgaris L.) by Trichoderma. Biological Control, United States, v. 51, n. 3, p.409-416, 2009.

LARKIN, R. P.; FRAVEL, D. R. Efficacy of various fungal and bacterial biocontrol organisms for control of fusarium wilt of tomato. Plant Disease, Saint Paul, v. 82, n. 9, p. 1022-1028, 1998.

LESLIE, J. F.; SUMMERELL, B. A. The Fusarium laboratory manual. Iowa: Blackwell Professional, 2006. $385 \mathrm{p}$.

LOHMANN, T. R.; PAZUCH, D.; STANGARLIN, J. R.; SELZLEIN, C.; NACKE, H. Seleção de isolados de Trichoderma spp. para controle de Sclerotium rolfsii em soja. Revista Brasileira de Agroecologia, Cruz Alta, v. 2, n. 2, p. 1665-1668, 2007.

LOZOVAYA, V. V.; LYGIN, A. V.; ZERNOVA, O. V.; LI, S.; WIDHOLM, J. M.; HARTMAN, G. L. Lignin degradation by Fusarium solani f.sp. glycines. Plant Disease, Saint Paul, v. 90, n. 1, p. 77-82, 2006.

MENEZES, J. P. Caracterização populacional $e$ molecular, e seleção de Trichoderma spp. para biocontrole de Fusarium sp. em crisântemo. 2007. Tese (Doutorado em Agronomia) - Universidade Federal de Santa Maria, Santa Maria.

MOREnO, J. A. Clima do Rio Grande do Sul. Porto Alegre: Secretaria da Agricultura, 1961. 73 p.

MOREIRA, F. M. S.; SIQUEIRA, J. O. Rizosfera. In: MOREIRA, F. M. S.; SIQUEIRA, J. O. Microbiologia e bioquímica do solo. 2. ed. Lavras: UFLA, 2006. p. 407447.

NELSON, P. E.; TOUSSON, T. A.; MARASAS, W. F. O. Fusarium species: an illustrated manual for identification. Philadelphia: Pennsylvania State University Press, 1983. $192 \mathrm{p}$.

OYARBIDE, F.; OSTERRIETH, M. L.; CABELLO, M. Trichoderma koningii as a biomineralizing fungus agent of calcium oxalate crystals in typical Argiudolls of the Los Padres Lake natural reserve (Buenos Aires, Argentina). Microbiological Research, Germany, v. 156, n. 2, p. 113-119, 2001.

PEREIRA, J. C. Interações entre as populações de actinobactérias e outros organismos na rizosfera. Seropédica: Embrapa Agrobiologia, 2000. 15 p. (Documentos, 118).

RAAIJMAKERS, J. M.; PAULITZ, T. C.; STEINBERG, C.; ALABOUVETTE, C.; MOËNNE-LOCCOZ, Y. The rhizosphere: a playground and battlefield for soilborne pathogens and beneficial microorganisms. Plant and Soil, Netherlands, v. 321, n. 1-2, p. 341-361, 2009.

ROY, K. W.; RUPE, J. C.; HERSHMAN, D. E.; ABNEY, T. S. Sudden death syndrome of soybean. Plant Disease, Saint Paul, v. 81, n. 10, p. 1100-1111, 1997.

SAMUELS, G. J.; DODD, S. L.; LU, B. S.; PETRINI, O.; SCHROERS, H. J.; DRUZHININA, I. S. The Trichoderma koningii aggregate species. Studies in Mycology, Utrecht, v. 56, n. 1, p. 67-133, 2006.

SIEGEL, S.; CASTELLAN, N. J. Estatística nãoparamétrica para ciências do comportamento. 2. ed. Porto Alegre: Artmed, 2006. 448 p.

SIVAN, A.; CHET, I. The possible role of competition between Trichoderma harzianum and Fusarium oxysporum on rhizosphere colonization. Phytopathology, Minnesota, v. 79, n. 2, p. 198-203, 1989.

TERMORSHUIZEN, A. J.; VAN RIJN, E.; VAN DER GAAG, D. J.; ALABOUVETTE, C.; CHEN, Y.; LAGERLOF, J.; MALANDRAKIS, A. A.; PAPLOMATAS, E. J.; RAMERT, B.; RYCKEBOER, J.; STEINBERG, C.; ZMORANAHUM, S. Suppressiveness of 18 composts against 7 pathosystems: variability in pathogen response. Soil Biology \& Biochemistry, Netherlands, v. 38, n. 8, p. 2461-2477, 2006.

TAMURA, K.; DUDLEY, J.; NEI, M.; KUMAR, S. MEGA 4: molecular evolutionary genetics analysis (MEGA) software version 4.0. Molecular Biology Evolution, Oxford, v. 24, n. 8, p. 1596-1599, 2007.

THOMPSON, J. D.; HIGGINS, D. G.; GIBSON, T. J. Clustal W: improving the sensitivity of progressive multiple sequence alignment through sequence weighting, position-specific gap penalties and weight matrix choice. Nucleic Acids Research, Oxford, v. 22, n. 22, p. 4673-4680, 1994.

WHITE, T. J.; BRUNS, T.; LEE, S.; TAYLOR, J. Amplification and direct sequencing of fungal ribosomal RNA genes for phylogenetics. In: INNIS, M. A.; GELFAND, D. H.; SHINSKY, J. J.; WHITE, T. J. (Ed.). PCR Protocols: a guide to methods and applications. New York: Academic, 1990. p. 315-322. 
